\title{
ROLE OF ULTRASONOGRAPHY IN EVALUATION OF OBSTRUCTIVE JAUNDICE
} Prakash Sharma $^{1 *}$, Subita Lalchan ${ }^{1}$, Prabhat Kumar Tiwari ${ }^{1}$

${ }^{1}$ Department of Radiology and Imaging, Manipal Teaching Hospital, Pokhara, Nepal.

*Correspondence to: Dr. Prakash Sharma, Department of Radiology and Imaging, Manipal Teaching Hospital, Pokhara,Nepal. Email:prakashshrm@yahoo.com

\begin{abstract}
Objective: To evaluate the sensitivity, specificity and accuracy of Ultrasonography in assessing the level and causes of obstruction in patients with obstructive jaundice. Materials and Methods: A total of 45 patients with clinical and laboratory features of biliary obstruction were included for statistical analysis. All these patients were evaluated with ultrasonography (USG). The levels of biliary obstruction were grouped as hilar, suprapancreatic and intra-pancreatic. Similarly, the probable causes were grouped as malignant or benign. Findings of USG were corroborated with cholangiographic, per-operative and/or histopathological findings (FNAC/Biopsy). Results: Most of the patients were in the age group of 61-80 years. There were 24 females (53\%) and 21 males (47\%). Accuracy of USG in identification of hilar, suprapancreatic and intrapancretic level of obstruction was $95.5 \%, 88.8 \%$ and $86.6 \%$, respectively. Sensitivity and Specificity of USG in identifying the hilar level of obstruction was $91.6 \%$ and $93.9 \%$, respectively. Similarly, sensitivity of USG in identifying the supra-pancreatic level of obstruction was $88.88 \%$ and specificity was $88.88 \%$. At the intrapancreatic level sensitivity was $83.33 \%$ and specificity was $90.47 \%$. Benign causes were seen in $53 \%$ and malignant causes in $47 \%$ of patients. Accuracy rate of USG in identifying the cause of obstruction was $82.2 \%$. Choledocholithiasis was the commonest cause for obstruction seen in $48.4 \%$ of patients. Carcinoma head of pancreas and cholangiocarcinoma were common malignant causes of obstruction (13.3\%). Sensitivity of USG in detecting malignant biliary obstruction was $80.95 \%$ and specificity was $83.33 \%$. Conclusion: Overall accuracy, sensitivity and specificity of USG in identification of hilar level of obstruction were higher than suprapancreatic and intrapancreatic levels..
\end{abstract}

Key words: Obstructive Jaundice, Ultrasonography.

\section{INTRODUCTION}

Obstructive jaundice is a condition associated with significant morbidity and mortality. It is due to the obstruction in the flow of bile which may be intrahepatic or extrahepatic. Early and accurate diagnosis of cause and level of obstruction is required for proper management. Commonly used procedures include Ultrasonography (USG), Computed Tomography (CT), Endoscopic retrograde cholangiopancreatography (ERCP), Percutaneoustranshepatic cholangiography (PTC) and Magnetic resonance cholangiopancreatography (MRCP).

Ultrasonography (USG) is cheap, non-invasive, readily available tool in the evaluation of obstructive jaundice. So, it is used as an initial screening tool.
This study was done to evaluate the sensitivity, specificity and accuracy of Ultrasonography in assessing the level and cause of obstruction in patients with obstructive jaundice.

\section{MATERIAL \& METHODS}

This prospective study was done in the Department of Radiodiagnosis and Imaging at Manipal Teaching hospital from February 2015 to January 2016. A total of 50 Patients of age more than 20 years attending Radiology department with clinical and laboratory features of biliary obstruction were included in the study. Ultrasonography positive cases were taken for further evaluation. The study was approved by institutional research committee. 
Patients were instructed to have at least 4-6 hours of fasting. The ultrasound examination was done using 3.5 to $5 \mathrm{MHz}$ probe with standard protocol in Logiq 400 and Accuson 300X machines. Examinations were performed by experienced Radiologist. Ultrasonic gel was used to ensure good contact between the transducer and the skin. The sonographic display parameters such as overall gain, focusing and depth gain compensation were properly adjusted. Scanning was done in at least three different planes. The level of obstruction and possible cause of obstruction was evaluated. Level of obstruction was grouped as hilar, suprapancreatic and intrapancreatic level. Causes were grouped as benign and malignant. Patient either underwent percutaneous transhepatic cholangiogram or ERCP within two weeks of ultrasound. The final diagnosis of the cause of obstruction was confirmed either by surgery, Biopsy or FNAC.

\section{STATISTICAL ANALYSIS}

Statistical analysis was performed using the standard Statistical Package for the Social Sciences (SPSS Inc., Chicago, IL, USA) version 16 for windows. Descriptive statistics were used to describe variables. The Fisher's exact test was used to examine the association between different variables. $P$ values of $<0.05$ were considered to be significant.

\section{RESULT:}

This prospective study was conducted in 50 patients with obstructive jaundice. Out of 50 patients, five had inadequate follow-up and hence excluded from the study. A total of 45 patients were included for statistical analysis.

The study population comprised of 21 males (47\%) and 24 females (53\%) with Male: Female ratio of 0.88:1. Age ranged from 22 to 82 years (Table 1 ) with the mean age of $63.0 \pm 11$.2. Most of the patients were in the age group 61-80 years. Based on the final diagnosis most common level of obstruction was at the intrapancreatic level (Figure1).

Out of 12 patients, USG was able to identify 11 patients of hilar obstruction. Sensitivity and Specificity of USG was $91.66 \%$ and $93.9 \%$, respectively in identifying the hilar level of obstruction in patients with obstructive jaundice. Similarly, accuracy rate was $95.5 \%$. Positive predictive value was $84.6 \%$ and negative predictive value was $96.8 \%$. These values were statistically significant $(p<0.0001)$ (Table 2$)$.

Sensitivity of USG in identifying the suprapancreatic level of obstruction was $88.88 \%$ and specificity was $88.88 \%$. Accuracy rate was $88.88 \%$. Positive predictive value and Negative predictive values were $66.66 \%$ and $96.9 \%$, respectively (Table 3 ).

Out of 24 patients, USG was able to correctly identify 20 patients of intrapancreatic level of biliary obstruction. Accuracy rate was $86.66 \%$. Positive predictive value was $90.9 \%$ and Negative predictive value was $82.6 \%$. These findings were statistically significant $(p<0.0001)$ (Table 4$)$.

Sensitivity of USG in detecting benign causes of biliary obstruction was $83.33 \%$ and specificity was $80.95 \%$. Positive predictive value was $83.33 \%$ and Negative predictive value was $80.95 \%$. These values were statistically significant $(p<0.0001)$ (Table 5).

Sensitivity of USG in detecting malignant biliary obstruction was $80.95 \%$ and specificity was $83.33 \%$. Positive predictive value and Negative predictive values were $80.95 \%$ and $83.33 \%$. These values were statistically significant $(p<0.0001)$ (Table 6).

Based on the final diagnosis most common cause of biliary obstruction was choledocholithiasis (48.8\%) (Table 7).

\section{DISCUSSION}

Ultrasound has been used as an initial imaging modality in evaluation of patients with obstructive jaundice.

Most of our patients with obstructive jaundice were in the age group of 61-80 years. Other authors have also noted the similar findings.5,7 This higher incidence of obstructive jaundice among older populations could be attributed to the lowered immunity hence the increased susceptibility to infections, stones and malignancy.

Females predominated in our study similar to findings of other studies ${ }^{5,7}$. Females are frequently exposed to the drugs like contraceptive pills which lead to gallbladder stone and they are also exposed to excess hormones during recurrent pregnancies 
which might favor gall stone formation.

Level of obstruction was divided into hilar(obstruction at or above the porta hepatis), Supra pancreatic (lower limit of hilar level to upper border of head of pancreas), and intrapancreatic (distal level of obstruction involving the pancreatic and ampullary region of common bile duct). In the present study most common level of obstruction was at intrapancreatic level which is similar to other studies $^{2}$. In contrast, hilar level of obstruction was seen in study by Ghimire R et al.3

In $53 \%$ of cases, causes of obstruction was due to benign pathologies. Choledocholithiasis was the most common etiology for obstructive jaundice in our case. Similarly, the most common causes in a study conducted by Karki s et al was due to benign etiologies, choledocholithiasis followed by common bile duct stricture ${ }^{4}$. Moawia Gameraddin et al also observed that biliary stones to be the commonest etiology for obstructive jaundice in their study. ${ }^{5}$ Saima Ikram, and colleague observed that in majority of cases, the causes of obstruction was due to benign causes (in 70\%). 6 But in a study conducted by ghimire R and colleagues, $3 \%$ of cases of obstructive jaundice was due to malignancy ${ }^{3}$.

In our study, ultrasonography was found to be most sensitive in diagnosing hilar obstruction (91.6\%) as compared to intrapancreatic and suprapancreatic pathologies whereas specificity rate was $94 \%$. We found that the diagnostic accuracy of ultrasound in diagnosis of obstructive jaundice was $95.5 \%$. I I ram $\mathrm{S}$ and colleagues observed lower accuracy rate than ours $(80 \%){ }^{6}$

In our observation, sensitivity of USG in detecting benign causes of biliary obstruction was $83.3 \%$ and in malignant biliary obstruction was $80.95 \%$. Similarly, specificity was $80.95 \%$ and $83.33 \%$, respectively for benign and malignant biliary obstruction. Karki $S$ and colleague found that sensitivity of USG in diagnosing choledocholithiasis was $100 \%$ but in cholangiocarcinoma it was $98.7 \%$. Similarly, their specificity rate for choledocholithiasis was $89 \%$ and in cholangiocarcinoma was $83 \% .{ }^{4}$ Andrea Piña and colleagues have observed ultrasonography to be less sensitive in detecting choledocholithiasis (sensitivity of $25 \%$ ) and biliary tract expansion (sensitivity of $66.5 \%)^{8}$

\section{CONCLUSION}

Overall accuracy, sensitivity and specificity of USG in identification of hilar level of obstruction were higher than suprapancreatic and intrapancreatic levels.

\section{REFERENCES}

1. Upadhyaya V, Upadhyaya DN, Ansari MA. Comparative assessment of imaging modalities in biliary obstruction. Indian J Radiol Imaging 2006; 16:577-582.

2. Laing FC, Jeffrey RB, Wing WW, Nybery DA. Biliary dilatation: Defining the level and cause by real- time US. Radiology. 1986; 160:39-42.

3. Ghimire R, Lohani B, Pradhan S. Accuracy of ultrasonography in evaluation of level and cause of biliary obstruction;a prospective study. Kathmandu Univ Med J (KUMJ) 2005; 3(9): 17-21.

4. Karki S, Joshi KS, Regmi S, Gurung RB, Malla B. Role of Ultrasound as Compared with ERCP in Patient With Obstructive Jaundice . Kathmandu Univ Med J (KUMJ) 2013; 11(3): 237- 240.

5. Gameraddin $M$, Omer $S$, Salih S, Elsayed SA, Alshaikh A. Sonographic Evaluation of Obstructive Jaundice. Open Journal of Medical Imaging 2015; 5: 24-29.

6. Ikram S, Alia N, Bokhari SHA, Rasool S. Evaluation of cases of obstructive jaundice by ultrasound and ERCP at tertiary care teaching hospital. Journal of university medical and dental college 2015;6(2):29-35.

7. Gamersddin $\mathrm{M}, \mathrm{Abdalgaffar} \mathrm{R}$, yousef $\mathrm{M}$. The role of ultrasound in diagnosis of obstructive Jaundice causes in Sudanese population. IOSR Journal of Nursing and Health Science 2013; 1(4): 25-28.

8. Piña A, Garzón M, Lizarazo Jl, Marulanda JC, Molano JC, Rey MH. Role of hepatobiliary ultrasound in the diagnosis of choledocolitiasis. Rev Col Gastroenterol 2010; 25(4):352-357. 
Table 1: Age distribution of patients.

\begin{tabular}{|l|l|l|l|l|}
\hline $\begin{array}{l}\text { Age } \\
\text { Group } \\
\text { (Years) }\end{array}$ & Male & Female & Total & $\%$ of Total Patients \\
\hline $20-40$ & 0 & 1 & 1 & $2.2 \%$ \\
\hline $41-60$ & 4 & 9 & 13 & $28.9 \%$ \\
\hline $61-80$ & 16 & 14 & 30 & $66.7 \%$ \\
\hline $81-100$ & 1 & 0 & 1 & $2.2 \%$ \\
\hline Total & 21 & 24 & 45 & $100 \%$ \\
\hline
\end{tabular}
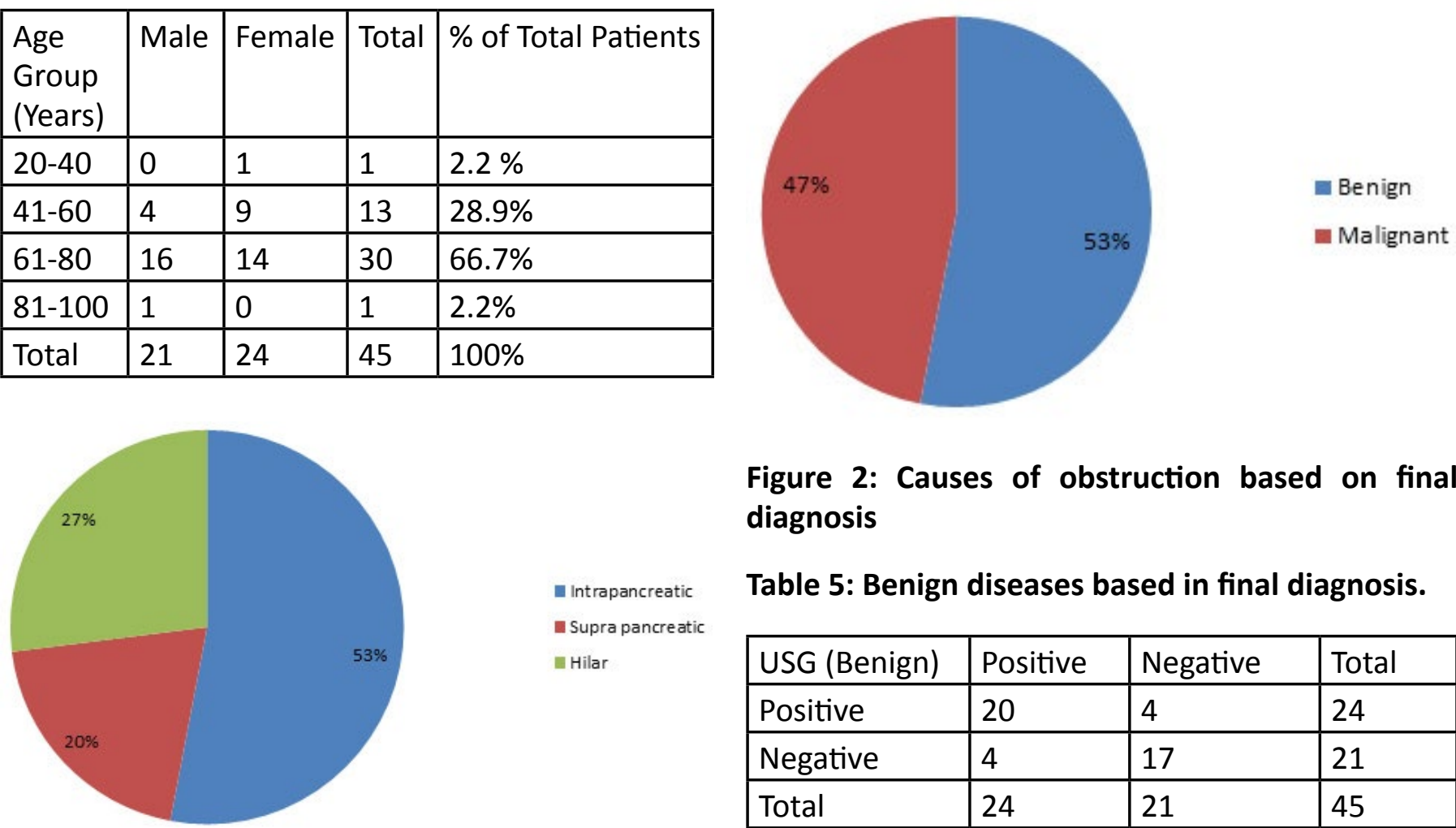

- Intrapancreatic

nSupra pancreatic

Figure 2: Causes of obstruction based on final diagnosis

Table 5: Benign diseases based in final diagnosis.

\begin{tabular}{|l|l|l|l|}
\hline USG (Benign) & Positive & Negative & Total \\
\hline Positive & 20 & 4 & 24 \\
\hline Negative & 4 & 17 & 21 \\
\hline Total & 24 & 21 & 45 \\
\hline
\end{tabular}

Figure 1: Level of obstruction based on the final diagnosis

Table 2: Patients with hilar level of obstruction

\begin{tabular}{|l|l|l|l|}
\hline USG & Positive & Negative & Total \\
\hline Positive & 11 & 1 & 12 \\
\hline Negative & 1 & 32 & 33 \\
\hline Total & 12 & 33 & 45 \\
\hline
\end{tabular}

Table 6: Malignant disease based on Final diagnosis

\begin{tabular}{|l|l|l|l|}
\hline USG (Malignant) & Positive & Negative & Total \\
\hline Positive & 17 & 4 & 21 \\
\hline Negative & 4 & 20 & 24 \\
\hline Total & 21 & 25 & 45 \\
\hline
\end{tabular}

Table 3: Patients with supra-panreatic level of obstruction

\begin{tabular}{|l|l|l|l|}
\hline USG & Positive & Negative & Total \\
\hline Positive & 8 & 4 & 12 \\
\hline Negative & 1 & 32 & 33 \\
\hline Total & 9 & 36 & 45 \\
\hline
\end{tabular}

Table 4: Patients with intra-pancreatic level of obstruction

\begin{tabular}{|l|l|l|l|}
\hline USG & Positive & Negative & Total \\
\hline Positive & 20 & 2 & 22 \\
\hline Negative & 4 & 19 & 23 \\
\hline Total & 24 & 21 & 45 \\
\hline
\end{tabular}

Table 7: Causes of biliary obstruction based on the final diagnosis.

\begin{tabular}{|l|l|l|}
\hline Causes of Biliary Obstruction & No of Patients & $\%$ \\
\hline Cholangiocarcinoma & 6 & 13.3 \\
\hline Carcinoma of Gall bladder & 4 & 8.8 \\
\hline Carcinoma head of Pancreas & 6 & 13.3 \\
\hline Ampullary Carcinoma & 1 & 2.2 \\
\hline Duodenal Malignancy & 2 & 4.4 \\
\hline Hepatocellular carcinoma & 2 & 4.4 \\
\hline Choledocholithiasis & 22 & 48.8 \\
\hline Stricture & 2 & 4.4 \\
\hline Total & 45 & 100 \\
\hline
\end{tabular}

